\title{
Comparaison de différentes techniques d'inoculation du piment par Phytophthora nicotianae var parasitica
}

\author{
MB Allagui ${ }^{1 *}, \mathrm{P}$ Lepoivre ${ }^{2}$ \\ 1 Laboratoire de cryptogamie, Inrat, rue Hédi-Karray, 2080 Ariana, Tunisie; \\ 2 Unité de phytopathologie, faculté universitaire des sciences agronomiques, 2, passage des Déportés, B-5030 Gembloux, Belgique
}

(Reçu le 22 mars 1996; accepté le 13 juin 1996)

\begin{abstract}
Résumé - Différentes techniques d'inoculation du piment, Capsicum annuum $\mathrm{L}$, ont été évaluées pour leur aptitude à reproduire correctement la spécificité parasitaire de $P$ nicotianae var nicotianae, espèce inféodée au tabac et non pathogène sur piment, $P$ capsici, espèce habituellement décrite et reconnue parasitaire sur piment et $P$ nicotianae var parasitica, la nouvelle forme décrite sur piment en Tunisie. Les différentes modalités d'inoculation incluant celles des racines, des tiges décapitées maintenues sur plante ou en survie, et des feuilles en survie ont été apliquées à six variétés de piment, dont $\mathrm{Pl}$ 201232, PI 201234 et CM 334 connues pour leur résistance à $P$ capsici. L'inoculation du système racinaire par dépôt d'un inoculum de 280000 zoospores suivi d'une incubation de 20 jours et de l'évaluation de l'intensité des nécroses racinaires, permet de reproduire la spécificité parasitaire des trois espèces de Phytophthora et le classement des variétés établi sur la base de leur sensibilité à $P$ capsici. Elle paraît bien adaptée aux objectifs recherchés. Les variétés résistantes à $P$ capsici ( $\mathrm{PI} 201232$ et $\mathrm{PI}$ 201234) se sont avérées sensibles à $P$ nicotianae var parasitica alors que la variété CM 334 est apparue résistante à ces deux pathogènes, confirmant le caractère spécifique de ce parasite du piment.
\end{abstract}

\section{Capsicum annum $\mathrm{L}=$ piment $/$ méthodes d'inoculation / Phytophthora nicotianae var parasitica}

Summary - Comparison of various inoculation methods of pepper with Phytophthora nicotianae var parasitica. Various inoculation methods for pepper were evaluated in order to reproduce the parasitic specificity of Phytophthora nicotianae var nicotianae, a specific tobacco pathogen, $\mathrm{P}$ capsici, the species usually found in pepper, and $\mathrm{P}$ nicotianae var parasitica, a new form recently isolated from pepper in Tunisia. The inoculation methods, including root inoculation, decapitated stem maintained on the plant or in vitro, and leaves kept alive in vitro, were compared on six pepper varieties including PI 201232, PI 201234 and CM 334, which are known for their resistance to P capsici. Root inoculation, performed by depositing 280000 zoospores followed by 20 days incubation and evaluation of the necrosis intensity, made it possible to mimic the rating of pepper varieties on the basis of their susceptibility to $\mathrm{P}$ capsici. Two of the varieties resistant to $P$ capsici (PI 201232 and PI 201234) appeared to be susceptible to $P$ nicotianae var parasitica while CM 334 was resistant to both pathogens, thus confirming the species status of that new pathogenic form in pepper.

pepper / inoculation methods / Phytophthora nicotianae var parasitica 


\section{INTRODUCTION}

Phytophothora capsici Léonian $(P C)$ a longtemps été considéré comme la seule espèce du genre Phytophthora capable d'infecter le piment (Léonian, 1922 ; Tucker, 1931 ; Satour et Butler, 1968 ; Messiaen et al, 1991). Alors que Phytophthora nicotianae var nicotianae (Pnn) est un parasite du tabac mais n'est pas pathogène sur piment, Phytophthora nicotianae var parasitica (Dastur) Waterh (Pnp) a été décrit pour la première fois en Tunisie en tant qu'agent pathogène responsable de dégâts dans les cultures de piment (Capsicum annuum L) (Allagui et al, 1995). Les symptômes de Pnp sur piment restent localisés au niveau des racines et du collet, progressent rarement sur la tige sans toutefois atteindre les ramifications ou les fruits. La mort de la plante ne survient que tardivement, le plus souvent au stade pleine production.

La mise au point d'une technique d'inoculation adéquate constitue un préalable à l'étude du couple piment/Pnp, tant pour ce qui est des recherches relatives à la pathogénie des souches qu'aux mécanismes de résistance de la plante ou aux méthodes de lutte.

De nombreuses techniques d'inoculation du piment par $P C$ ont été décrites. Nous pouvons distinguer, en fonction de l'organe de la plante qui est inoculé, les méthodes d'inoculation des racines, des tiges (décapitées ou en survie) et des feuilles (maintenues sur la plante ou en survie).

Les différentes méthodes d'inoculation du système racinaire du piment par $P C$ se différencient par l'âge des plantes inoculées, la forme de l'inoculum (mycélium, zoospores), la concentration en zoospores, la conduite des plantes après I'inoculation (Kimble et Grogan, 1960 ; Reifschneider et al, 1986 ; Palloix et al, 1988a ; Bosland et Lindsey, 1991).

Les tiges décapitées de piment ont également été utilisées pour l'inoculation à l'aide d'une pastille mycélienne qui est déposée à la surface de la section ainsi mise à nu (Pochard et Chambonnet, 1971). Une fois inoculées, les tiges de piment sont ensuite incubées en serre ou maintenues en survie dans des tubes en plongeant leur base dans de l'eau (Clerjeau et al, 1976).

Dans le but d'identifier des sources de résistance au "mildiou foliaire" causé par $P C$, le système foliaire a également servi à l'inoculation par pulvérisation d'une suspension de zoospores de
$P C$, suivie de l'incubation des plantes dans une atmosphère à forte hygrométrie (Barksdale et al, 1984 ; Kim et al, 1989 ; Alcantara et Bosland, 1994). Les feuilles de piment peuvent aussi être maintenues en survie, entières dans des boîtes de Petri (Clerjeau et al, 1976), ou sous forme de disques foliaires flottant sur une solution de benzimidazole (Ponchet et al, 1975) avant d'être inoculés par des disques mycéliens ou des zoospores de $P C$.

Cet article compare différentes techniques d'inoculation du piment par Pnp. Le critère le plus important dans l'évaluation de ces techniques est l'expression correcte du pouvoir pathogène de Pnp et des deux autres espèces de Phytophthora $(P n n$ et $P C$ ) utilisées comme référence. L'inoculation doit également satisfaire à des exigences de rapidité de la réponse, de facilité des manipulations, tout en permettant une quantification de la réaction des plantes inoculées.

\section{MATÉRIEL ET MÉTHODES}

\section{Matériel végétal}

Six variétés de piment, Capsicum annuum $\mathrm{L}$, ont été utilisées (tableau I) dans nos essais. Les variétés de référence sensibles à $P n p$ et à $P c$ ont été Beldi, Yolo Wonder et HV 2. Les variétés de référence résistantes à Pc ont été PI 201232, PI 201234 et CM 334.

\section{Matériel cryptogamique}

L'isolat de Pnp (236) dont dérive la souche monospore (236-4) a été isolé en Tunisie d'une plante de piment présentant des symptômes de flétrissement et de pourriture racinaire, tandis que les souches de référence $P n n$, non pathogène sur piment, et $P c$, fortement pathogène sur les variétés de piment sensibles, nous ont été aimablement envoyées par MM Bonnet (Antibes) et Palloix (Montfavet) (tableau II).

Ces souches ont été maintenues à la température ambiante du laboratoire $\left(20-25^{\circ} \mathrm{C}\right)$ et conservées sur PDA (potato dextrose agar) ou CMA (corn meal agar) par repiquages successifs tous les 3 à 4 mois sur le même milieu nutritif.

\section{Inoculum fongique}

Les pastilles mycéliennes utilisées pour l'inoculation des plantes ont été prélevées à la périphérie de colonies âgées de 4 à 7 jours sur CMA. 
Tableau I. Variétés de piment cultivées et sauvages utilisées dans les tests d'inoculation.

$\begin{array}{ll}\text { Variétés } & \text { Origine } \\ & \\ \text { Beldi } & \text { Locale (Tunisie) } \\ \text { Yolo Wonder } & \text { Commerciale } \\ \text { PI 201232 } & \text { Inia (Saragosse, Espagne) } \\ \text { PI 201234 } & \text { Inia (Saragosse, Espagne) } \\ \text { CM 334 } & \text { Inia (Saragosse, Espagne) } \\ \text { HV 2 } & \text { Inra (Montfavet, France) }\end{array}$

Caractéristique a

Sensible au champ à Pnp

Sensible à $P C$

Résistance à Pc (Kimble et Grogan, 1960)

Résistance à PC (Kimble et Grogan, 1960)

Résistance à $P c$ (Guerrero et Laborde, 1980)

Haploïde doublé, sensible à Pnp (Allagui, 1994).

a $P n p=$ Phytophthora nicotianae var parasitica $; P_{C}=$ Phytophthora capsici.

Tableau II. Identification des souches de Phytophthora utilisées dans les tests d'inoculation.

$\begin{array}{llll}\text { Code souche } & \text { Espèce a } & \text { Plante hôte } & \text { Origine } \\ & & & \\ P n p(236-4) & P n p & \text { Piment (Tunisie) } & \text { Inrat (Tunisie) } \\ P n n(329) & P n n & \text { Tabac (Grèce) } & \text { Inra (Antibes) } \\ P c(101) & P c & \text { Piment (France) } & \text { Inra (Montfavet) }\end{array}$

a $P n p=$ Phytophthora nicotianae var parasitica $; P n n=$ Phytophthora nicotianae var nicotianae $; P C=P h y t o p h t h o r a$ capsici.

Pour l'obtention des zoospores, les souches ont été cultivées pendant 12 jours sous lumière diffuse naturelle, à $23-26{ }^{\circ} \mathrm{C}$, sur milieu nutritif gélosé à base d'une décoction de pois (Tello et al, 1991) ; les colonies ont ensuite été couvertes d'eau distillée stérile pendant 3 jours avant d'être placées à $4{ }^{\circ} \mathrm{C}$ pendant 1 heure afin que les sporocystes libèrent de grandes quantités de zoospores.

\section{Méthodes d'inoculation}

\section{Inoculation des plantules par dépôt d'une suspension de zoospores déposée au collet}

Les graines des différentes variétés ont été désinfectées à l'eau de javel ( $40 \mathrm{~g}$ de $\mathrm{Cl}_{2}$ actif par litre) pendant 10 minutes puis rincées trois fois avec de l'eau stérile.

Le substrat utilisé pour le semis et la plantation était constitué d'un mélange de fumier, de sable, de terre argileuse et de perlite $(1: 1: 1: 1, v / v)$. Ce mélange a été préalablement désinfecté par traitement à la vapeur pendant 90 minutes.

Quinze jours après le semis, les plantules ont été repiquées en pots de $10 \mathrm{~cm}$ de diamètre contenant le même substrat désinfecté à la chaleur. Pour permettre une meilleure percolation de l'inoculum, un léger bina- ge destiné à casser la croûte superficielle formée autour du collet et à ameublir le substrat a été pratiqué au cours de la semaine suivant le repiquage. Quinze jours après leur transplantation, les plantules (stade deux feuilles en formation) ont été inoculées en arrosant leur collet avec un volume d'eau variant entre 2,5 et $8 \mathrm{~mL}$ afin de maintenir le nombre de zoospores aux environs de 280000 ; les plantes témoins ont été traitées par l'eau. Un léger arrosage a été effectué immédiatement après l'inoculation pour entraîner les zoospores le long du système racinaire et corriger les différences de volumes d'eau utilisés pour l'inoculum. Les arrosages ont été ensuite pratiqués tous les 3 à 4 jours en fonction de l'humidité du substrat. Les plantes, ainsi traitées, ont été maintenues 20 jours dans une serre dont la température était située entre 18 et $26^{\circ} \mathrm{C}$.

La notation de l'intensité des nécroses racinaires a été réalisée quand les plantes des variétés Yolo Wonder et HV 2 inoculées par Pnp (236-4) présentaient $100 \%$ de mortalité et celles de PI 201234, $75 \%$ de mortalité. Pour ce faire, le système racinaire des plantules a été délicatement détaché du substrat terreux par trempage dans une bassine d'eau et les symptômes évalués conformément à l'échelle d'intensité suivante (Palloix et al, 1988a) :

$0=$ plantule saine, aucune nécrose sur les racines,

$0,5=$ nécrose limitée à l'extrémité des radicelles, 1 = nécrose stoppée à la moitié inférieure des racines primaires, 
2 = nécrose n'atteignant par le collet,

$3=$ nécrose atteignant le collet et les radicelles adventives,

4 = pourriture de l'hypocotyle,

5 = mortalité de la plante suite à une nécrose généralisée.

\section{Inoculation des tiges décapitées}

Nous avons appliqué la méthode décrite par Pochard et Chambonnet (1971). Le semis a été réalisé dans un substrat terreux dans une logette dont la température avoisine $20-30{ }^{\circ} \mathrm{C}$ avec un éclairage de 16 heures/jour. Deux semaines après le semis, les plantules ont été repiquées en pots dans le même substrat. Les tiges des plantes âgées de 48 j (ébauches florales) ont été ensuite sectionnées au dessus de la dernière feuille qui avait atteint son plein développement. Une pastille mycélienne de $6 \mathrm{~mm}$ de diamètre a été déposée à la surface de la section et recouverte par du papier d'aluminium pour maintenir une humidité élevée. Les témoins ont été inoculés avec un implant gélosé de CMA. Les plantes ont été ensuite incubées à $20-30^{\circ} \mathrm{C}$ avec une photopériode de 16 heures/jours. La longueur de la portion nécrosée de la tige a été périodiquement mesurée.

\section{Inoculation des tiges et feuilles maintenues en survie en boîtes de Petri}

Des plantes âgées de 55 jours (formation des boutons floraux), semées et repiquées comme nous l'avons indiqué précédemment, ont été utilisées. Les tiges ont été coupées à la base, juste au dessus de l'insertion des cotylédons et à une distance de $70 \mathrm{~mm}$, mesurée à partir de cette première section. La troisième feuille de ces mêmes plantes a été coupée au niveau de la base du limbe et son extrémité parfois coupée de telle sorte que la feuille puisse être mise à plat dans une boîte de Petri. Les feuilles et les tiges effeuillées ainsi préparées ont été désinfectées par trempage dans une solution de $\mathrm{NaClO}(2 \%)$ pendant 4 minutes, rincées trois fois à l'eau distillée stérile et séchées sur un papier filtre stérile.
Les tiges et les feuilles ont été ensuite étalées dans des boîtes de Petri (une tige ou feuille par boîte de $90 \mathrm{~mm}$ de diamètre) sur un papier filtre humidifié par de l'eau distillée stérile. L'inoculation de la tige a été effectuée en déposant une pastille mycélienne de $6 \mathrm{~mm}$ de diamètre au contact de l'extrémité basale. Le même inoculum a été déposé sur la face supérieure du limbe foliaire à l'emplacement d'un trou de $4 \mathrm{~mm}$ de diamètre réalisé dans la partie basale du limbe à l'aide d'un emporte-pièce.

Après leur fermeture par du Reynolon, toutes les boîtes de Petri ont été mises à incuber à $25^{\circ} \mathrm{C}$ et à l'obscurité. La longueur des nécroses a été périodiquement mesurée sur les tiges et, trois jours après l'inoculation, sur l'axe de la nervure principale des feuilles.

\section{RÉSULTATS}

\section{Inoculation par dépôt de zoospores au collet des plantules}

Les plantules des variétés Yolo Wonder et HV 2 ont montré $75-80 \%$ de mortalité dès le quatrième jour après l'inoculation aussi bien par $P C$ (101) que par Pnp (236-4).

Yolo Wonder et HV 2 ont confirmé leur très grande sensibilité à $P C(101)$ tandis que les trois autres variétés sont apparues très résistantes à cette même souche (intensité des symptômes comprise entre 0,1 et 0,6 ).

Vingt jours après l'inoculation par Pnp (236-4), les variétés Yolo Wonder, HV 2 et PI 2012034 présentaient toutes une intensité élevée des symptômes (notation comprise entre 4,8 et 5 ), tandis que la variété PI 201232 apparaissait légèrement moins attaquée (intensité moyenne des symptômes de 4) et la variété CM 334 résistante (notation moyenne 0,3) (tableau III).

Les cinq variétés étudiées sont toutes apparues immunes à Pnn (329).

Tableau III. Intensité des symptômes a du système radiculaire et limite de variation (entre parenthèses) 20 jours après l'inoculation de $P n p$ (236-4), $P C$ (101) et $P n n$ (329), par dépôt des zoospores au collet des plantules.

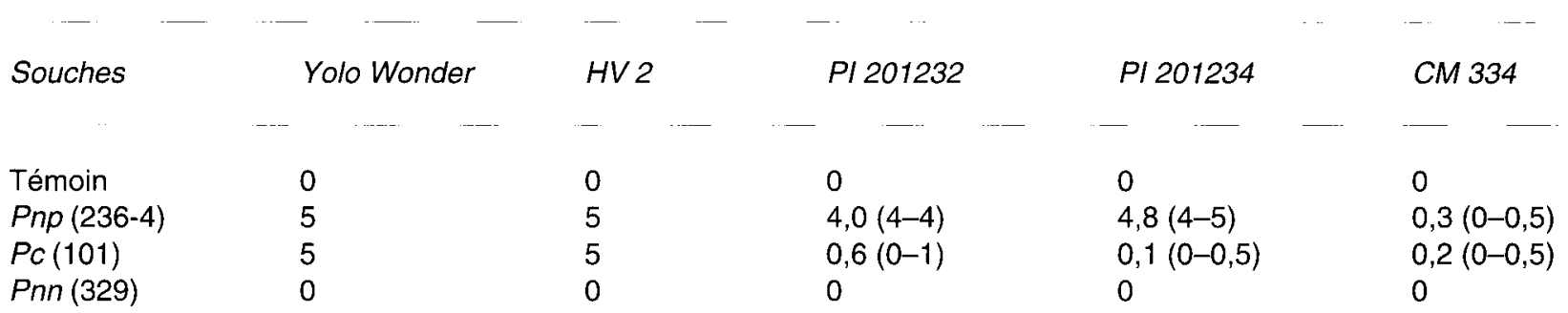

a L'échelle de notation (Palloix et al, 1988a) varie entre 0 (plante saine) et 5 (plante morte). Chaque valeur est la moyenne de cinq répétitions. 


\section{Inoculation des tiges décapitées}

La figure 1 montre l'accroissement dans le temps de la longueur des nécroses sur les tiges décapitées et inoculées par Pnp (236-4), Pc (101) ou Pnn (329).

La souche Pnp (236-4) a provoqué sur les tiges des variétés Beldi et Yolo Wonder le développement de nécroses sèches dont les longueurs sont passées de $9 \mathrm{~mm}$ (trois jours après l'inoculation) à environ $30 \mathrm{~mm}$ (après 15 jours
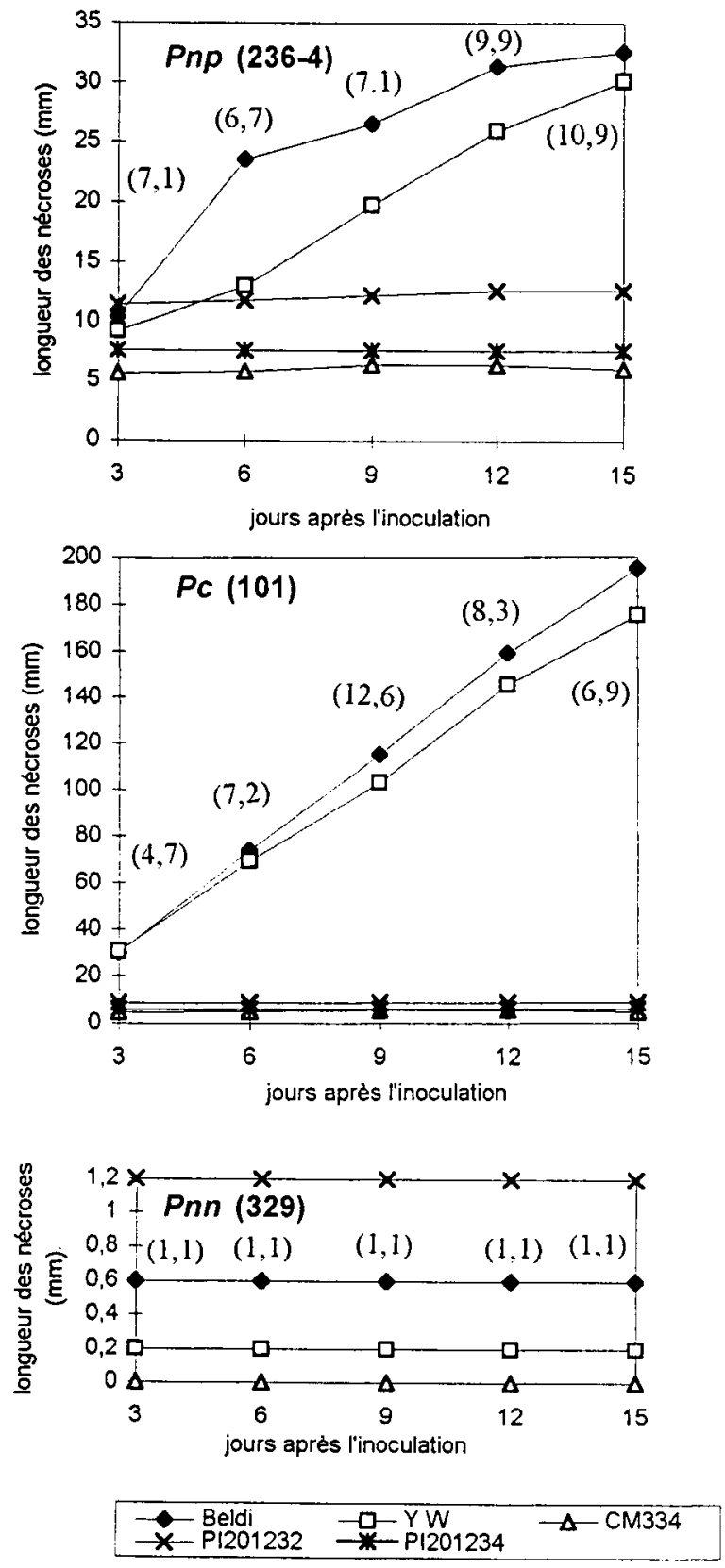

Fig 1. Longueur des nécroses (en $\mathrm{mm}$ ) en fonction du temps sur tiges décapitées de différentes variétés de piment (âge : 48 jours) inoculées par Pnp (236-4), $P_{C}$ (101) ou $P_{n n}$ (329). Les chiffres entre parenthèses indiquent pour chaque temps d'inoculation les valeurs des PPDS au seuil de $5 \%$. d'incubation) tandis que le développement des nécroses était stoppé, dès le troisième jour après l'inoculation, sur les variétés CM 334, PI 201232 et PI 201234.

La souche $P C$ (101) inoculée sur les variétés Beldi et Yolo Wonder a provoqué en 15 jours le développement d'une nécrose molle sur la totalité des tiges (longueurs variant entre 175 et $195 \mathrm{~mm}$ ) tandis que, sur les variétés $\mathrm{CM} 334, \mathrm{PI}$ 201232 et PI 201234, inoculées par cette même souche, ces nécroses se sont limitées à quelques $\mathrm{mm}$ et n'ont pas progressé pendant toute la durée de l'essai.

Sur toutes les variétés, la souche Pnn (329) a produit des nécroses dont la longueur n'a pas évolué au-delà de $1 \mathrm{~mm}$. Ce comportement est identique à celui des plantes témoins.

\section{Inoculation des tiges en survie}

La figure 2 montre l'évolution dans le temps des longueurs des lésions nécrotiques induites par les trois souches de Phytophthora sur les tiges maintenues en survie.

Les nécroses dues à Pnp (236-4) observées sur les variétés CM 334 et PI 201234 se sont peu développées $(2,8 \mathrm{~mm}$ et $7,2 \mathrm{~mm}$ respectivement après 10 jours d'incubation) alors que celles observées sur les variétés Beldi, Yolo Wonder et PI 201232 atteignaient environ $35 \mathrm{~mm}$ dans le même temps.

Sur les variétés Beldi et Yolo Wonder, la souche $P C$ (101) a produit des nécroses qui ont envahi l'ensemble des tiges après six jours d'incubation, alors que les variétés CM 334 et PI 201234 sont restées très peu affectées par $P C$ (101) pendant toute la durée de l'essai (nécroses de moins de $5 \mathrm{~mm}$ ) et que la variété $\mathrm{PI} 201232$ présentait un comportement intermédiaire entre ces deux groupes.

La souche Pnn (329) a provoqué de très petites nécroses qui n'ont pas évolué quelle que soit la variété. Aucune lésion n'a été observée chez le témoin.

\section{Inoculation des feuilles en survie}

Pour l'ensemble des variétés, les nécroses induites par les souches Pnp (236-4) et Pc (101) ne sont pas significativement différentes entre elles tandis que les lésions induites par Pnn (329) ont été identiques à celles des deux autres 
souches pour CM 334 et PI 201232 mais significativement plus petites sur les trois autres variétés (tableau IV).

La variété Beldi est significativement plus sensible à $P n p(236-4)$ que les autres variétés qui ne
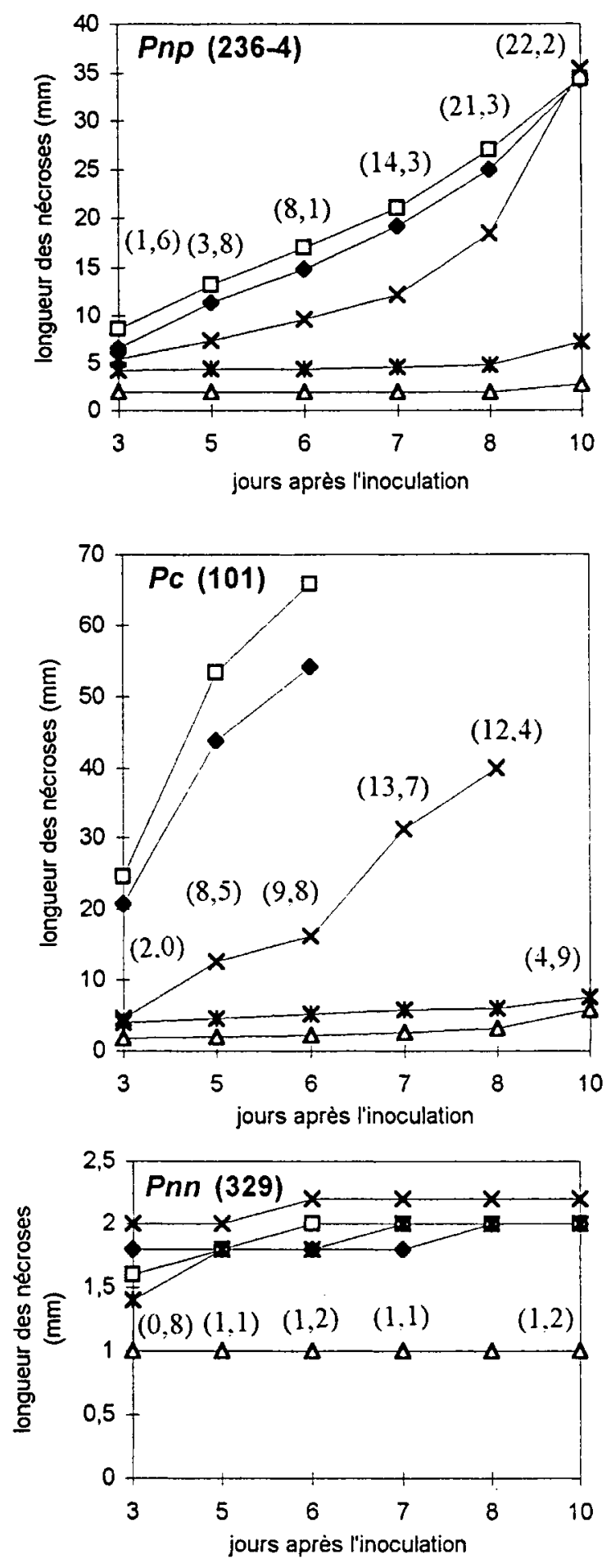

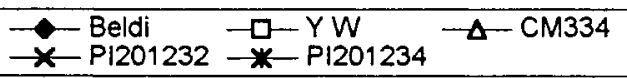

Fig 2. Longueur des nécroses (en mm) en fonction du temps sur tige en survie de différentes variétés de piment (âge : 55 jours) inoculées par Pnp (236-4), Pc (101) ou Pnn (329). Les chiffres entre parenthèses indiquent pour chaque temps d'incubation les valeurs des PPDS au seuil de $5 \%$. diffèrent pas entre elles. PI 201232 est légèrement plus sensible que les autres variétés à $P C$ (101), tandis qu'aucune différence entre variétés n'est observée avec la souche Pnn (329).

\section{DISCUSSION ET CONCLUSION}

La technique d'inoculation par application de zoospores au collet de plantules confirme le caractère non pathogène de Pnn (329), normalement inféodé au tabac, alors que la souche $P c$ (101), pathogène sur piment, reproduit correctement le comportement des variétés de référence vis-à-vis de cette espèce. Nous pouvons séparer le groupe des variétés sensibles représenté par Yolo Wonder et HV 2, de celui des variétés résistantes formé par CM 334 et $\mathrm{Pl} 201234$ et, dans une moindre mesure, celui de la variété $\mathrm{PI}$ 201232. Ces résultats confirment des études antérieures (Kimble et Grogan, 1960 ; Guerrero et Laborde, 1980 ; Palloix et al, 1988b ; Gil Ortega et al, 1991) utilisant $P C$ dans des tests d'inoculation des racines.

L'inoculation avec Pnp (236-4), par arrosage du collet des plantules de piment par une suspension de zoospores (tableau III), a montré que les variétés Yolo Wonder, HV2 et PI 201234 sont très sensibles à Pnp (236-4) (''appareil racinaire est totalement nécrosé) alors que la variété $\mathrm{PI}$ 201232 présente une moindre sensibilité mais que seule la variété $C M 334$ est résistante (absence de lésion nécrotique sur les racines). Ce comportement variétal envers Pnp (236-4) est globablement différent de celui qui est observé avec $P C$, confirmant ainsi le caractère particulier des souches de Pnp isolées de piment.

L'inoculation des racines reproduit les conditions d'infection naturelles du piment par Pnp puisque cette espèce est habituellement observée sur le collet et les racines des plantes. Aucun test de résistance variétale n'ayant encore été réalisé à ce jour au champ avec $P n p$, nous utiliserons néanmoins ces résultats comme référence dans l'évaluation des autres méthodes.

L'inoculation par la souche $P C$ (101) des tiges décapitées donne un classement des variétés de référence qui concorde avec leur niveau de sensibilité au champ (fig 1) et aucune des variétés n'a été affectée par la souche Pnn (329). Le pouvoir pathogène de $P C(101)$, le caractère non pathogène de $P n n$ sur piment ainsi que le spectre de sensibilité variétale à $P C$ (101) sont donc correctement reproduits par le test d'inoculation des tiges décapitées. 
Tableau IV. Longueur $(\mathrm{mm})$ des nécroses sur les feuilles en survie et erreur standard. Inoculation par Pnp (326-4), Pnn (329) et $P C$ (101).

$\begin{array}{lccccr}\text { Souches } & \text { Beldi } & \text { Yolo Wonder } & \text { CM 334 } & \text { Pl201232 } & \text { Pl 201234 } \\ & & & & & \\ \text { Pnp (236-4) } & 42,8 \pm 9,0 & 29,0 \pm 5,8 & 28,8 \pm 1,9 & 29,4 \pm 6,9 & 25,0 \pm 6,3 \\ \text { PC (101) } & 32,0 \pm 2,4 & 32,4 \pm 1,6 & 28,4 \pm 2,9 & 40,2 \pm 6,7 & 28,4 \pm 7,8 \\ \text { Pnn(329) } & 17,0 \pm 8,2 & 16,2 \pm 10,9 & 31,4 \pm 5,8 & 29,4 \pm 8,7 & 11,4 \pm 4,6\end{array}$

Notation 3 jours après l'inoculation. Chaque valeur est la moyenne de cinq répétitions.

Cependant, le classement de la résistance variétale à Pnp (236-4) établi sur la base du test d'inoculation des tiges décapitées n'est pas identique à celui obtenu avec le test d'inoculation des racines. La variété $\mathrm{PI} 201234$ sensible à Pnp (236-4) sur la base des résultats de l'inoculation racinaire s'est montrée résistante à cette même souche lors du test d'inoculation de la tige décapitée.

Le test des tiges en survie (fig 2) a globablement montré des résultats identiques à ceux du test des tiges décapitées pour des temps d'incubation similaires. La variété PI 201232 s'est cependant montrée sensible à $P n p(236-4)$ et à $P C$ (101) avec les tiges en survie, alors qu'elle était considérée comme résistante avec le test des tiges décapitées.

La seconde différence entre les deux tests tiges (décapitées ou en survie) et racines concerne la variété $\mathrm{Pl} 201234$. Cette variété est résistante à Pnp avec les tests tiges au même degré que CM 334 mais, avec le test de l'inoculation des racines, apparaît sensible (équivalente à Yolo Wonder) alors que CM 334 demeure résistante (tableau III).

Le test feuille en survie a donné des résultats différents des autres tests à tous les niveaux (tableau IV). Cette technique n'a pas caractérisé correctement le pouvoir pathogène des espèces de Phytophthora; Pnn (329), non pathogène sur piment, a pu envahir les tissus foliaires de certaines variétés au même titre que les souches des espèces $P C$ et $P n p$ pathogènes sur cette plante. Ce test est également inapproprié pour évaluer la résistance variétale ; CM 334, qui est une variété résistante à $P c$ (test d'inoculation des racines ou des tiges) a montré, par ce test, un niveau de sensibilité identique à celui de Yolo Wonder. L'âge des feuilles qui peut être en liaison avec leur sénescence, ne permet pas d'expliquer ces résultats contradictoires avec les autres tests, puisque nous avons obtenu la même sévérité des symptômes en utilisant des feuilles en survie provenant de plantes plus jeunes (résultats non publiés). Ces résultats corroborent ceux de Clerjeau et al (1976) qui ont conclu que les feuilles de piment en survie constituent un mauvais matériel pour discriminer l'agressivité des isolats de $P C$ ou bien la résistance des plantes de piment à ce parasite. En inoculant des feuilles de piment sur plante avec des zoospores de $P C$, Kim et al (1989) n'ont pas trouvé de différence entre les variétés sensibles et résistantes, que ce soit avec des feuilles jeunes ou adultes. En revanche, Barksdale et al (1984) ont rapporté que l'inoculation par $P C$ des feuilles de piment maintenues sur la plante donnait des résultats reproduisant la sensibilité des variétés observées dans un sol naturellement infesté par $P c$. Dans le cas de Pnp, il faut cependant rappeler que ce parasite n'attaque que le collet et les racines et n'affecte pas naturellement les feuilles.

Pour Pnp, la méthode d'inoculation globalement la plus fiable est celle qui consiste à appliquer une suspension de zoospores au collet des plantes de piment. Cette technique permet une évaluation rapide (moins de 20 jours), est facile à mettre en œuvre et aboutit à une évaluation quantitative des nécroses racinaires. Sur la base de ce test, les deux variétés PI 201232 et PI 201234 se sont montrées sensibles à $P n p$, alors que $\mathrm{CM} 334$, déjà connu pour sa résistance à $P C$, s'est également révélée résistante vis-à-vis de ce nouveau pathogène du piment, Pnp. II serait important de confirmer cette résistance par des observations au champ afin de pouvoir mettre en œuvre des programmes d'amélioration ciblant spécifiquement Pnp.

Nos résultats suggèrent également qu'il serait possible de différencier $P n p$ et $P C$ en utilisant, par exemple, la variété PI 201234 (résistante à $P C$ et sensible à $P n p)$, une autre variété sensible à $P C$ et résistante à $P n p$ et une troisième sensible aux deux espèces comme Yolo Wonder. 
Cette hypothèse demande à être confirmée par l'inoculation d'un plus grand nombre de souches de ces différentes espèces.

\section{REMERCIEMENT}

Le premier auteur remercie la Fondation internationale pour la science pour son soutien financier.

\section{RÉFÉRENCES}

Alcantara TP, Bosland PW (1994) An inexpensive disease screening technique for foliar blight of chile pepper seedling. Hortscience 29, 1182-1183

Allagui MB (1994) Phytophthora nicotianae var parasitica resistance ability of some pepper varieties. Capsicum Eggplant News 13, 93-96

Allagui MB, Marquina JT, Mlaiki A (1995) Phytophthora nicotianae var parasitica pathogène du piment en Tunisie. agronomie 15, 171-179

Barksdale TH, Papavisas GS, Johnson SA (1984) Resistance to foliar blight and crown rot of pepper caused by Phytophthora capsici. Plant Dis 68, 506509

Bosland PW, Lindsey DL (1991) A seedling screen for Phytophthora root rot of pepper, Capsicum annuum. Plant Dis 75, 1048-1050

Clerjeau M, Pitrat M, Nourrisseau JG (1976) La résistance du piment (Capsicum annuum) à Phytophthora capsici. IV. Étude de l'agressivité de divers isolats, au niveau des feuilles, des tiges et du collet de plantes sensibles et résistantes. Ann Phytopathol 8, 411-423

Gil Ortega R, Espanol CP, Zueco JC (1991) Genetics of resistance to Phytophthora capsici in pepper line "SCM 334". Plant Breed 107, 50-55

Guerrero AM, Laborde JA (1980) Current status of pepper breeding for resistance to Phytophthora capsici in Mexico. Proceeding of the Eucarpia Capsicum Working Group 4th Meeting, Wageningen, 52-56
Kim YJ, Hwang BK, Park KW (1989) Expression of age-related resistance in pepper plants infected with Phytophthora capsici. Plant Dis 73, 745-747

Kimble KA, Grogan RG (1960) Resistance to Phytophthora root rot in pepper. Plant Dis Report 44, 872-873

Léonian LH (1922) Stem and fruit blight of peppers caused by Phytophthora capsici sp Nov. Phytopathology 12, 401-408

Messiaen CE, Blancard D, Rouxel F, Lafon R (1991) Les maladies des plantes maraîchères ( $3^{\mathrm{e}}$ éd). Inra, Paris

Palloix A, Daubèze AM, Pochard E (1988a) Time sequences of root infection and resistance expression in an artificial inoculation method of pepper with Phytophthora capsici. J Phytopathol 123, 12-24

Palloix A, Daubèze AM, Pochard E (1988b) Phytophthora root rot of pepper influence of host genotype and pathogen strain on inoculum densitydisease severity relationships. J Phytopathol 123, 25-33

Pochard E, Chambonnet D (1971) Méthodes de sélection du piment pour la résistance au Phytophthora capsici et au virus du concombre. Ann Fac Scie Agric Univ Torino 7, 270-281

Ponchet J, Andréoli C, Augé G (1975) Essai de caractérisation du pouvoir pathogène chez quelques espèces du genre Phytophthora. Ann Phytopathol 7, 105-114

Reifschneider FJB, Café-Hilo AC, Rego AM (1986) Factors affecting expression of resistance in pepper (Capsicium annuum) to blight caused by Phytophthora capsici in screening trials. Plant Pathol 35, 451-456

Satour MM, Butler EE (1968) Comparative morphological and physiological studies on the progenies from intraspecific matings on Phytophthora capsici. Phytopathology 58, 183-192

Tello J, Vares F, Lacasa A (1991) Analisis de muestras. In: Manual de laboratorio, diagnostico de hongos, bacterias y nematodos fitopatogenos (Direccion general de sanidad de la produccion agraria, ed), Madrid, $485 \mathrm{p}$

Tucker CM (1931) Taxonomy of the genus Phytophthora de Bary. Res Bull Mo Agric Exp St, $153 \mathrm{p}$ 